\title{
Study on Revision of Disclosure Obligation Under Marine Insurance Clauses in Chinese Maritime Law
}

\author{
Li Junfeng ${ }^{1}$, Wang Deling ${ }^{2, *}$, Wang Yubao ${ }^{1}$ \\ ${ }^{1}$ Law School, Shanghai Maritime University, Shanghai, China \\ ${ }^{2}$ Merchant Marine College, Shanghai Maritime University, Shanghai, China
}

Email address:

Jeffersonlijf@hotmail.com (Li Junfeng),dlwang@shmtu.edu.cn (Wang Deling),wangyb@njcit.cn (Wang Yubao)

${ }^{*}$ Corresponding author

To cite this article:

Li Junfeng, Wang Deling, Wang Yubao. Study on Revision of Disclosure Obligation Under Marine Insurance Clauses in Chinese Maritime Law. International Journal of Business and Economics Research. Vol. 9, No. 3, 2020, pp. 103-108. doi: 10.11648/j.ijber.20200903.12

Received: March 5, 2020; Accepted: April 8, 2020; Published: April 23, 2020

\begin{abstract}
Since implemented on July 1, 1993, the Maritime Code of the People's Republic of China has played an irreplaceable role in adjusting the legal relationship in maritime commerce. In recent years, great changes have taken place in the practice of international shipping. To further meet the practical needs of international shipping and judicial practice, the revision of the Maritime Code of the People's Republic of China (for short is CMC) has been put on the agenda officially. The obligation of disclosure occupies an important position in the entire marine insurance legal system, and has continuously changed and evolved over hundreds of years. As the birthplace of marine insurance law, the United Kingdom passed a new insurance law in 2015, named as Insurance Act (IA2015), abolishing the unlimited notification mode for the insured existed for more than 100 years, and introducing a fair presentation obligation and related relief mechanism, which can be described as a revolutionary measure. At present, China's marine insurance is booming, and marine insurance activities need to be guided by accurate, mature and complete legal provisions. Research on the reform of the disclosure obligation model combined with the development of the British insurance law, clarifying its connotation and specific content is helpful to promote relevant adaptation in China, and has important theoretical significance and practical value for revising relevant sections of CMC.
\end{abstract}

Keywords: Revision, CMC, Disclosure Obligation, IA2015, MIA1906

\section{Introduction}

Since the implementation of the CMC, it has played a vital role in the equal protection of the legal interests of the parties concerned, keeping the international shipping order, and promoting PRC trade and economic development. However, $\mathrm{CMC}$ has been lagging to some extent in recent years, compared with development of the society, the formulation and revision of international conventions, improving the domestic legal system, the changes in shipping trade practices, and the demand for judicial practice. [1]

Disclosure obligation is one of the core of marine insurance rules and plays an important role in marine commercial activities. First of all, it requires the disclosure of information affecting insurance matters, which can ensure the stability of the legal relationship of marine insurance contracts. Second, it helps the insurer assess the underwriting risks as accurately as possible and enhances the performance of the insurance contract. Third, it is conducive to ensuring the sustainability of maritime business activities.

As the origin of the disclosure, Britain has been constantly revising and improving relevant system for more than a century. With the development of insurance practice, disclosure obligation in Marine Insurance Act 1906 (MIA1906) is no longer appropriate. The latest British insurance law in 2015 abolished the principle of Utmost good faith (in fact, as better explained below, the Act has abolished the consequences of the breach of utmost good faith. The Act has not abolished the name of "utmost good faith," but has kept it as an "interpretative principle.") [2], and introduced the Duty of fair presentation, which can be described as a major revision to the disclosure obligation in marine insurance law. The mode of disclosure obligation in marine insurance has undergone a fundamental change. 
Maritime law is naturally foreign-related and international, which is determined by the nature of international shipping as a derivative service of international trade. As the maritime law served to international ocean transportation, the adjustment of maritime transportation relations should be in line with international standards. Undoubtedly, the promulgation and implementation of the CMC has a great historical significance, it ended the Chinese maritime disputes in the field of maritime business can not be based on the era, for the Chinese maritime trial provides an important legal basis. [3] Likewise, the CMC has a strong international character as well. Thus, revision of CMC needs to constantly learn from and absorb international conventions, international practices and relevant contents of foreign laws, strengthen comparative law research, improve legal transplantation techniques, and accurately achieve the legislative purpose. [1]

Considering the current marine insurance clauses in CMC mainly refer to MIA1906, the revision work of CMC should adhere to the principle of unity of theory and practice. As mentioned earlier, under the premise of significant changes in the duty of disclosure system, to ensure that the revision of $\mathrm{CMC}$ is better in line with international standards, it is necessary to study how to learn from the development experience of Britain in the current legal environment. Therefore, making an in-depth analysis of the theoretical and practical value of the duty of disclosure, and selecting an appropriate mode of disclosure, has become one of the core issues to be solved urgently in PRC marine insurance law.

\section{Introduction to the Recent Revision Progress of China's Maritime Law}

The current CMC is a law drafted, deliberated and coordinated by tens of thousands of people over 40 years from 1950s to 1990s. [4] And as a special law born in a specific era, CMC represents the highest level that PRC can reach in this field at that time.

The drafters at the time proceeded from the actual in China, based on the main maritime international conventions (Hague-Visby rules, Hamburg rules, etc.), absorbed reasonable elements of international practices and folk rules, drew lessons from the standard contracts with wide influence (mainly those drew up by BIMCO), and transplanted the terms of other jurisdictions, such as MIA1906 in the chapter of marine insurance.

Since its promulgation and implementation, CMC has provided an important legal basis for PRC maritime trials. It is proved that this law is effective in improving and perfecting PRC's maritime legal system, safeguarding the legitimate rights and interests of all parties concerned, regulating PRC's international shipping market, shortening the distance between China and international shipping advanced economies, and promoting the development of China's shipping industry and foreign economic and trade undertakings. For the effect, more than $90 \%$ of the provisions in CMC derived from the laws of various countries and or international conventions have been endorsed and welcomed by countries around the world since its promulgation. [5]

As well known, Lord Holmes's proposal "the life of the law has not been logic, it has been experience". And in the 20 years since the $\mathrm{CMC}$ was promulgated and implemented, great changes have taken place in PRC and the world international shipping market, as well as international shipping regulations, and the international trade situation. CMC should also make corresponded adjustments as the following changes:

1) Significant changes have taken place in the world international trade and shipping situation, and the influence of the Chinese factor on the international shipping market has become greater and greater. At the same time, the trading elements of international shipping are also different from those of the last century. And the more detailed and specialized division of international shipping and the impact of the Internet wave all require CMC to keep up with the trend of the times, so that it can be given full play to its role in guiding international shipping practice.

2) In recent years, with the changes of shipping strength and import and export volume in various countries, new game trends have also emerged towards international shipping legislation. [6] Regarding how to balance the interests of all parties, and even the interests of nations, is an important aspect of maritime law revision that needs to be focused on.

3) As mentioned before, the current CMC is drawn up on the basis of a large number of references to international shipping rules, including international conventions and commercial practices, transplanted some extraterritorial laws. With the changes in international maritime conventions, standard contracts and other shipping rules in recent years, CMC should continue to maintain an open and inclusive attitude, actively absorb the beneficial and reasonable parts and should be further amended.

Considering the above factors, after repeated calls from the industry, the revision of CMC has been officially put on the agenda. On November 5, 2018, the Ministry of Transport of The PRC promulgated the Revised Draft for Comment of CMC (for short is Revised Draft of MOT) and solicited public opinions. At the same time, a revised CMC statement was issued by the Ministry of Transport of The PRC, which clearly states: 8 . Supplementary guarantee and disclosure obligation system. According to the British insurance law and the Chinese insurance practice, the uncertainty of the guarantee is supplemented and the standard of disclosure obligation shall be adjusted. ${ }^{1}$ On February 1, 2019, the Ministry of Transport of The PRC issued a notice on the 2019 legislative plan, which clearly stated the CMC revision belongs to category I projects and needs to be completed for 
review within the year. ${ }^{2}$ Nowadays, the research on the revision of CMC is in full swing.

\section{The Connotation and Evolution of the Disclosure Obligation}

Before analyzing the connotation of the duty of disclosure in marine insurance law, it is necessary to have a certain understanding of the origin and historical background of the duty of disclosure. Disclosure, as early as 1766, Judge Mansfield discussed the duty of disclosure in the famous Carter v. Boehm case. ${ }^{3}$ After a century and a half of refinement of relevant jurisprudence, the duty of disclosure was finally codified in MIA 1906, and it is a concrete embodiment of the principle of Utmost good faith. Utmost good faith, called "uberrima fides" in Latin, whilst there may be instances in which an insured can breach its pre-contractual duty of utmost good faith other than by breach of the duty to make disclosure and only to make representations that are true, in practical terms non-disclosure and misrepresentation are the most important aspects of the pre-contractual duty of utmost good faith as it applies to insureds. [7]

According to articles 18 to 20 of MIA1906 and important case law explaining these provisions, the duty of disclosure is only part of the principle of Utmost good faith, and even can be called the core content of the principle of Utmost good faith. The principle of utmost good faith is the upper concept of the duty of disclosure, which is all-inclusive and continuous. And the duty of disclosure system embodies the concept and spirit contained in the principle of Utmost good faith-the essence of a transaction is that one party should convince the other party that the facts he accepts are exactly what he was told, otherwise, the transaction then will be legally ineffective. The purpose of the duty of disclosure, based on the implied duty of utmost good faith, is to assist the insurer in its risk assessment. [8] And in the pre-contract period the principle of utmost good faith creates wellestablished duty owed by the insured to disclose material facts and to refrain from making untrue statements when negotiating the contract. [9]

The legal provisions on the obligation of disclosure can be divided into limited disclosure obligation and unlimited disclosure obligation in theory. Infinite disclosure doctrine, also known as active disclosure doctrine, legally defines disclosure obligation as an active obligation, that is, no matter whether the insurer inquires or not, the insured or the policyholder must actively inform all important information they know. As for limited disclosure, it is also called passive notification or question-and-answer notification. Under this mode, the insurer needs to take the initiative to ask the applicant or the insured about the situation it wishes to know, and the insurer shall answer truthfully. The mode of limited notification does not mean that the insured's notification

2 http://xxgk.mot.gov.cn/jigou/fgs/201903/t20190304_3171499.html.

3 (1766) 3 Burr. 1905, 1910-1912. obligation can be waived. The difference between limited disclosure and unlimited disclosure lies in the way of performing the obligation of disclosure, including content, scope, time, degree, legal consequences, etc.

Article 18 of MIA1906 embodies the three meanings of the unlimited notification (active notification) mode: first, although it is difficult to confirm, the insured should still make statements to the insurer on all the important situations, that is, the scope and content of notification shall be determined by the insured first; second, the insurer has the right to inquire about what it considers important; third, the liability arising from the insured's breach of the duty of disclosure is not affected by the insurer's inquiry or not by the insurer impact. These three levels of relations are organic, unified and related to each other.

Today, the principle of utmost good faith has undergone gradual development and change, and finally it can be said to be nearly extinct. The IA2015 was approved by the Queen on February 12, 2015 and entered into force in August 2016. It can be called the most important change in the history of British insurance since the 1906 Marine Insurance Act. On the obligation of disclosure, specifically, the obligation of MIA1906 to "inform all important situations" was abolished, but instead a Before of contract of insurance is entered into, the insured must make to the insurer a fair presentation of the risk. $^{4}$ And consequently, utmost good faith and the new duty of fair presentation are now "entirely independent and unrelated" principles. [10]

Based on retaining the basic connotation of the old provisions, it is stipulated in the new act that the insured should, on the one hand, actively inform the important information and, on the other hand, provide sufficient information to induce the insurer to make further inquiries, which requires the insurer to act more actively, thus sharing the burden of informing to a certain extent. Second, the remedies for breach of the obligation of disclosure have changed from single to multiple, abandoning the old law which does not distinguish the violation state, that is, and adopting the subjective basis of breach of contract whether the status is deliberate or reckless so as to give the insurer different relief channels. Article 8 of the new law introduces a concept of "qualified breach", so that not all breaches of the law can be applied to the relief provided by the new law, but to determine whether it is "qualified" first.

Prior to that, the only relief that can be given to the insurer in violation of Article 18 or Article 20 of MIA1906 is to terminate the contract. Under the new law, insurers enjoy different remedies based on different circumstances. The remedies are stipulated in section 4-6 of part 1 of appendix 1 of the new law. If the breach of the obligation of fair representation is not intentional or reckless, the remedies available to the insurer will depend on what measures the insurer will take in response to the risk if it has been reasonably stated by the insured. According to Article 4, Part 1 of Appendix 1, if the insurer will completely refuse to

4 IA 2015 S. 3 (1) 
accept the insurance, that is, it will not enter into an insurance contract with the insured at all, then the insurer has the right to terminate the insurance contract without assuming any liability for compensation, and must return the premium already collected.

Articles 5 and 6 of the appendix stipulate the legal effect if the insurer enters into a contract on different terms. ${ }^{5}$ Among them, when the insured's behavior constitutes other eligible defaults (unintentional or reckless), if the insurer will enter into a contract but will charge a higher premium, the insurer may reduce the amount of compensation claimed in proportion. The " proportionate remedies" mentioned here is a fundamental change. ${ }^{6}$ Because the point of disclosure in insurance is to make the information available so that the underwriter is able to assess the significance of the disclosed information and reach a decision on whether to insure and on what terms.[11] Meanwhile, in business insurance, under both MIA 1906 and IA 2015, the relevant duty encompasses the disclosure of material facts to the other party to the contract and not to misrepresent facts. [12]

\section{Provisions and Comments on Disclosure Obligation in CMC}

The CMC's provisions on the disclosure obligation are Article 222 and Article 223. ${ }^{7}$ These articles can be analyzed

\footnotetext{
5 IA 2015 Schedule 1, Part 1, S. 5 If the insurer would have entered into the contract, but on different terms (other than terms relating to the premium), the contract is to be treated as if it had been entered into on those different terms if the insurer so requires. IA 2015 Schedule 1, Part 1, S. 6 (1) In addition, if the insurer would have entered into the contract (whether the terms relating to matters other than the premium would have been the same or different), but would have charged a higher premium, the insurer may reduce proportionately the amount to be paid on a claim.

6 IA 2015 Schedule 1, Part 1, S. 6 (2) In sub-paragraph (1), "reduce proportionately" means that the insurer need pay on the claim only $\mathrm{X} \%$ of what $\mathrm{i}$ would otherwise have been under an obligation to pay under the terms of the contract (or, if applicable, under the different terms provided for by virtue of paragraph 5), where $-x=$ premium actually charged/higher premium $* 100$.

7 Article 222 The insured shall, before the contract is concluded, truthfully inform the insurer of the material circumstances which the insured has knowledge of or ought to have knowledge of in his ordinary business practice and which may have a bearing on the insurer in deciding the premium or whether he agrees to insure or not.

The insured need not inform the insurer of the facts which the insurer has knowledge of or ought to have knowledge of in his ordinary business practice if about which the insurer made no inquiry.

Article 223 Upon failure of the insured to truthfully inform the insurer of the material circumstances set forth in Paragraph 1 of Article 222 of this Code due to his intentional act, the insurer has the right to terminate the contract without refunding the premium. The insurer shall not be liable for any loss arising from the perils insured against before the contract is terminated.

If, not due to the insured's intentional act, the insured did not truthfully inform the insurer of the material circumstances set out in Paragraph 1 of Article 222 of this Code, the insurer has the right to terminate the contract or to demand a corresponding increase in the premium. In case the contract is terminated by the insurer, the insurer shall be liable for the loss arising from the perils insured against which occurred prior to the termination of the contract, except where the material circumstances uninformed or wrongly informed of have an impact on the occurrence of such perils.
}

as follows.

China does not have the concept of the principle of utmost good faith, but the principle of good faith, as a basic principle of civil law, has been established in the regulation of civil legal relations. And the Maritime Code adopts a subjective standard while the Insurance Act requires the insurer to inquire. In such circumstance, it is clear that Chinese marine insurance law substantially contains the principle of utmost good faith, although there is no express provision setting out a concept of utmost good faith. [13] The CMC still adopts the active notification mode similar to MIA 1906. Regarding the remedy for breach of disclosure obligation, Articles 223 and 224 of the CMC both take into account the subjective fault of the insured. Non-disclosure or misrepresentation can be made intentionally, by gross negligence, negligently or innocently. [14] If the insured intentionally violates the obligation of disclosure, the insurer shall have the right to terminate the contract without refunding the insurance premiums, and the insurer shall not be liable for any compensation for the insured accidents before the contract is terminated. The insurer may choose to rescind the contract or increase the insurance premium (paragraph 2 of Article 223) if it does not violate the obligation of disclosure due to the fault of the insured. Comparatively speaking, the obligation of unlimited disclosure stipulated in China's marine insurance law is not as strict as that stipulated in British law. That is because, as mentioned paragraph 2 in Article 222, stipulated that if the insurer knows or should know in ordinary business, the insured need not inform if the insurer has not inquired. There are some imperfections in the provisions on the duty of disclosure in CMC. For example, there are no clear rules on what is important, the scope of " has knowledge of or ought to have knowledge of " and the connotation and extension of important situations, which are more general and difficult to judge in judicial practice. On the subject of performing the obligation of disclosure, there is no distinction between the insured and applicant, and they are not explicitly included in the insurance broker and the insured's agent, etc., which may easily lead to confusion in judicial practice.

According to the previous analysis, from the perspective of legal origin or legislative technology, through technical means of legal transplantation, Chapter 12 of CMC mainly draws on the relevant content of MIA1906. [15] Under British law, the connotation of disclosure obligation has changed greatly, the revision of CMC should pay attention to this change, and should study it, rationally absorb the reasonable part of it, and combine China's marine insurance practice to improve the relevant provisions of the CMC.

\section{Comments on the Stipulation of Disclosure Obligation in the Revised Draft of MOT and Suggestions}

In the revised draft of CMC from the Ministry of Transport of The PRC, the provisions on the duty of disclosure and the 
revision instructions are as follows.

Related key points of revision:

1) Improve the system of the insured's active disclosure obligation to reflect the "bidirectional" requirement of the principle of good faith.

2) Article 14.8 The insured shall, before the contract is concluded, truthfully inform the insurer of the material circumstances which the insured has knowledge of or ought to have knowledge of in his ordinary business practice and which may have a bearing on the insurer in deciding the premium or whether he agrees to insure or not.

If the insurer does not inquire about the following circumstances, the insured need not inform:

1) The information already notified by the insured is sufficient to make the insurer aware of the need to inquire further;

2) Relevant information that the insurer has knowledge of or ought to have knowledge of in his ordinary business practice

Article 14.9 Upon failure of the insured to truthfully inform the insurer of the material circumstances set forth in paragraph 1 of Article 14.8 of this Law due to his intentional act, the insurer has the right to terminate the contract without refunding the premium. The insurer shall not be liable for any loss arising from the perils insured against before the contract is terminated.

If the insured fails to truthfully inform the insurer of the important information specified in the first paragraph of article 14.8 of this law due to no intentional act of the insured

If it is not caused by the intention of the insured that the important situation stipulated in Article 14.8, paragraph 1 of this law has not been truthfully notified to the insurer, the insurer has the right to terminate the contract or request a corresponding increase in insurance premiums. If the insurer canceled the contract before the commencement of the insurance liability, he shall refund all the premiums, but shall have the right to collect the handling charges. If the insurer canceled the contract after the commencement of the insurance liability, except for voyage insurance contract, the insurance premium from the date of cancellation of the contract to the date of expiration of the insurance period shall be returned to the insured; the insurer shall be liable for compensation for the loss caused by the insurance accident before the contract is terminated; however, the important information not informed or wrongly informed has an impact on the occurrence of the insurance accident excepted.

The insurance premium shall not be refunded if the insurer terminates the voyage insurance contract after the insurance liability has begun in accordance with the provisions of the preceding paragraph.

The rescinding right of the contract stipulated in this article shall be extinguished if it is not exercised for more than 30 days from the date when the insurer has knowledge of or ought to have knowledge of termination.

Compared with the current $\mathrm{CMC}$, there are the following differences in this version of the revised proposal,

1) Mixed notification mode,

2) The consequences of the insurer's failure to fulfill the obligation of disclosure are further refined.

3) Increase the time limit for the insurer to terminate the contract, it shall be deemed as scheduled period.

After analyzing the provisions on the duty of disclosure in the above-mentioned revised proposal, this paper put forward the improving suggestions as below:

1) The scope of the subject of disclosure obligation should be expanded. The subject of disclosure obligation stipulated in CMC only refers to the insured, and does not cover policy holder, the agent of the insured, the insurance broker and other subjects in the process of concluding the insurance contract, which has a certain narrow sense, furthermore, it also leads to logical confusion in the main provisions of disclosure obligation in our insurance legal system. Compared with IA2015, although the provisions on the subject of the insurance contract are limited to the insurer and the insured, the provisions on "Knowledge of insured" stipulate in detail the matters that the insured knows and ought to know.

When the insured is an individual, it is deemed that he knows all the information known by the " responsible for the insured's insurance". "Responsible for the insured's insurance" includes the risk manager of the insured and any employee assisting in data collection or negotiation of insurance clauses, as well as individuals acting as brokers of the insured. When the insured is not an individual (such as a company), the knowledge of the insured's senior management or the person in charge of the insurance of the insured can be directly attributed to the information of the insured. In other words, the subject of performing the obligation of disclosure is still limited to the insured, meanwhile stipulates the attribution of informed consequences of many other legal subjects that may be related to the insured.

2) Criteria for judging the boundaries of disclosure obligation should be clearly defined. The scope of the obligation of disclosure is mainly reflected which could be summed up as "facts that the insurer knows or ought to know in the ordinary business" based on relevant cases analysis.

In this way, only when the insurer takes the initiative to inquire, the insured has the obligation to inform, otherwise, the determination of this fact can constitute a waiver of the obligation to inform. "The insurer knows or ought to know" includes two types of situations: first, the insurer actually knows the relevant situations clearly; second, prudent insurers should know the relevant information in their normal business scope. "Prudent insurer" is an abstract concept of illusion, which adopts the level of knowledge about relevant situations of insurers, who have mastered general professional knowledge and business ability in the marine insurance market within a certain period of time.

There are two reasons for adding the cautious insurer 
standard when explaining "ought to know". First, adopting the "actual insurer ought to know" standard means that the judgment of "should know" is completely handed over to the specific insurer of the contentious case, which is easy for the insurer to excuse himself for various reasons and should not know the relevant situation. The prudent insurer standard takes into account the average standard of most insurers in the same marine insurance market.

Then the judgment of "prudent insurers ought to know" is particularly important. IA2015 provides such a path: the information that the insurer should know includes two types: one type is the information that the insurer's employees or agents know and should reasonably transmit to the insurer, and the other type is the information within the insurer's organization that can be found by making reasonable efforts for relevant insurers. The situations that the insurer is presumed to know also include two types: one is common knowledge or well-known situations, and the other is things which an insurer offering insurance of the class in question to insureds in the field of activity in question would reasonably be expected to know in the ordinary course of business.

3) Important information should be clarified. How to clarify important information can be used for reference in theory from the IA2015 stipulation that the insurer should know and presume to know. In judicial practice, expert assistant system in China's civil procedure law can be introduced. The insurer and the insured respectively look for their own expert witnesses to testify and refute in court, then the judge can interrogate the expert assistant of both parties according to his/her authority and make the final determination.

4) A more detailed distinction should be made as to the circumstances under which the right to terminate the contract is applicable and the corresponding increase in insurance premiums is required.

\section{Conclusions and Prospects}

The change of disclosure obligation mode reflects the legislators' continuous balancing of the interests of the insurer and the insured. And the boundaries of disclosure obligation can be clearly defined after IA2015 came out under the wording of "fair presentation obligation". Meanwhile, procedure of revision for CMC has accelerated, and the China Maritime Insurance Law is also facing reform. In the reform process, reasonable parts of IA2015 can be used for reference. This will not only help to track the latest legislative achievements, but also provide a broad legislative and judicial international comparative perspective for the study of the revision of Chapter 12 of the $\mathrm{CMC}$ when the revision of the $\mathrm{CMC}$ has been officially put on the agenda.

\section{References}

[1] Wang Shumei, Hou Wei. Some opinions on the revision of the Maritime Code Chinese [J]. Journal of Maritime Law. 2010, $21(2): 3-5$.

[2] Attilio M. Costabel. "Utmost Good Faith" in Marine Insurance: A Message on the State of the Dis-Union [J]. Journal of Maritime Law \& Commerce, Vol. 48, No. 1, January, 2017, p 1.

[3] He Lixin, Liang Jiacheng. Report on the 25-year judicial application of the Chinese Maritime Code [J]. Chinese Journal of Maritime Law. Vol. 29 No. 2. p 42.

[4] Zhu Zengjie. Review and prospect on the Maritime Code of the People's Republic of China [J]. Chinese Journal of Maritime Law. Vol. 24 No. 3. p 3.

[5] Chen Lunlun, Yan Yunzhi. Forty Years of Chinese Maritime Law: Historical Development and Prospect [A]. Journal of Zhejiang Ocean University (Humanities Science). 2019 Vol. 36 No. 3 .

[6] Li Guoguang. Playing the maritime judicial functions and promoting the development of maritime legal system [J]. Chinese Journal of Maritime Law. 2012, 23 (3): 3-5

[7] Jonathan Gilman, Robert Merkin, Claire Blanchard, Mark Templeman. Arnould's Law of Marine Insurance and Average [M]. 18th, London: Sweet \& Maxwell, 2013. At page 599.

[8] Chang Kaunchun. Commentaries on the Recent Amendment of the Insurance Law of the People's Republic of China Regarding Insurance Contracts from the Perspective of Comparative Law [J]. Washington University Global Studies Law Review, 2011 Vol. 10 Issue 4. At page 764.

[9] John Birds, Ben Lynch, Simon Milnes. Mac Gillivray on Insurance Law. 12th, London: Sweet \& Maxwell, 2012. para. 17-003..

[10] R. Merkin, Colinvaux's Law of Insurance [M]. 11th edn, Sweet \& Maxwell 2017 at 6-006.

[11] Yang Yiqing. The Past and Future of Utmost Good Faith: A Comparative Study Between English and Chinese Insurance Law [D]. University of Exeter. January, 2017. At page 135.

[12] Özlem Gürses. Marine Insurance Law [M]. Taylor \& Francis, 2016. At page 51 .

[13] Jing Zhen. Remedies for Breach of the Pre-contract Duty of Disclosure in Chinese Insurance Law [J]. Connecticut Insurance Law Journal. March, 2017. Volume 23 At page 5.

[14] Hjalmarsson Johanna, Huang Dingjing. Insurance Law in China [M]. CRC Press, 2014. At page 103.

[15] Guo Yu. The Spirit of Maritime Law-China's Practice and Theory [M]. Peking University Press. 2005: 87. 